Article

\title{
Equilibrium between Road Traffic Congestion and Low-Carbon Economy: A Case Study from Beijing, China
}

\author{
Shuxia Yang ${ }^{1,2, *}, \mathrm{Yu} \mathrm{Ji}^{2}{ }^{2}$, Di Zhang ${ }^{2}$ and Jing Fu ${ }^{2}$ \\ 1 Beijing Key Laboratory of New Energy and Low-Carbon Development, North China Electric Power \\ University, Beijing 102206, China \\ 2 School of Economics and Management, North China Electric Power University, Beijing 102206, China; \\ jiyu1225jiyu@ncepu.edu.cn (Y.J.); zhangdi4796@163.com (D.Z.); fujing_ncepu@163.com (J.F.) \\ * Correspondence: bjysx216@126.com
}

Received: 29 October 2018; Accepted: 28 December 2018; Published: 4 January 2019

check for updates

\begin{abstract}
China has allocated low-carbon targets into all regions and trades, and road traffic also has its own emission reduction targets. Congestion may increase carbon emissions from road traffic. It is worthwhile to study whether it is possible to achieve the goal of road traffic reduction by controlling congestion; that is, to achieve the equilibrium between traffic congestion and a low-carbon economy. The innovation of this paper is mainly reflected in the innovative topic selection, the introduction of a traffic index, and the establishment of the first traffic congestion and low-carbon economic equilibrium model. First, the relevant calculation method of the traffic index is introduced, and the traffic index is used to quantify the traffic congestion degree. Using the traffic index, GDP, and road passenger traffic volume, a nonlinear regression model of road traffic carbon emissions is constructed. Then, the calculation method of the carbon emission intensity of road traffic in the region is proposed. The equilibrium model of traffic congestion and a low-carbon economy is constructed to look for the degree of road traffic congestion that may occur under the permitted carbon emission intensity. Taking Beijing, where electric vehicles account for less than $3 \%$ of the total vehicles, as an example, it is difficult to achieve the equilibrium target between road traffic congestion and a low-carbon economy by alleviating traffic congestion in 2020. If the target of traffic carbon emission reduction in 2020 is adjusted from $40 \%-45 \%$ to $19.7 \%$ based on 2005 , the equilibrium will be achieved. A negative correlation between road traffic carbon emissions and the reciprocal of the traffic index (1/TI) is found after eliminating the effects of GDP and PTV (road passenger traffic volume). As the traffic index decreases by units, the carbon emission reduction accelerates. The results show that carbon reduction targets cannot be simply allocated to various industries. The results of the research on the degree of the impact of traffic congestion on carbon emissions can be used as a basis for carbon reduction decisions of the traffic sector. The research method of this paper can provide a reference for the study of the equilibrium of traffic congestion and a low-carbon economy in other regions.
\end{abstract}

Keywords: Traffic congestion; low-carbon economy; equilibrium; carbon emission reduction; multivariate nonlinear regression model; road traffic carbon emissions

\section{Introduction}

Being low carbon has become a common concern of the whole world. China has put low carbon into the hard constraints of economic development. It is generally believed that traffic congestion will increase carbon emissions. In China, however, some urban traffic congestion problems represented by Beijing are becoming more and more prominent, which brings great resistance to carbon emission reduction in road traffic. 
Beijing is the capital of China, with a permanent resident population of 21.707 million at the end of 2017. It has $22,242 \mathrm{~km}$ of road mileage, $6360 \mathrm{~km}$ of urban road, 450.117 million road passenger traffic volume, 193.737 million tons of road freight traffic volume, and 5.638 million civil vehicles [1]. Since 2017, an average of 725,000 traffic permits for vehicles to Beijing per week have been processed [2]. These vehicles not only bring serious traffic congestion, but also emit a lot of air pollutants. Vehicle emissions have become the greatest contributor of PM2.5. The PM2.5 source apportionment report released by the Beijing Environmental Protection Bureau shows that the contribution of regional transmission is about $28 \%$ to $36 \%$, and the contribution of local pollution emission accounts for $64 \%$ to $72 \%$. In the contribution of local pollution, the proportion of motor vehicle emissions is the highest, reaching $31.1 \%$ [3]. With the continuous development of Beijing's economy and road traffic, the high-intensity and low-efficiency use of cars has increased the traffic flow of road networks. Road traffic congestion has also occurred in advance, resulting in slow dissipation of road network vehicles during the morning and evening peak hours and prolonging the time of congestion $[4,5]$.

In 2009, at the World Climate Conference in Copenhagen, Chinese Premier, Jiabao Wen, made a commitment on behalf of China. By 2020, the carbon dioxide emission per unit of GDP will fall by $40 \%-45 \%$ compared with 2005 . The development of a low-carbon economy has brought enormous challenges to China, which include the development of its economy and the improvement of people's livelihoods. Weidong Liu, Dadao Lu, and Lei Zhang (2010) analyzed the main factors affecting the country's carbon emissions, and calculated the emission reduction capacity of major emission reduction channels. Then, they gave a series of hard constraint and rigid index recommendations. They were full of confidence in achieving the goal of a low-carbon economy in China [6]. Jianwei Wang, Ping Li, and Jie Gao (2012) studied the regional division of carbon emissions in China's industry, and classified Beijing into an optimized area; that is, an area with a high level of economic development, transportation industry development, and carbon emission; large load of environmental resources; and a large potential for carbon emission reduction [7]. From the research results of Shuxia Yang et al. (2018), it can be seen that the market cultivation of electric vehicles in Beijing will take time [8]. Therefore, the challenges posed by the increasingly congested Beijing road traffic to the low-carbon economy are still difficult to estimate.

Due to the contradiction between the transportation capacity and rapid growth of traffic demand, traffic congestion in Beijing is becoming more and more serious, and road traffic carbon emissions are increasing year by year. The goal of a low-carbon economy has brought considerations about various carbon emission reduction measures in China. Studying the balance between a low-carbon economy and traffic congestion is of great significance to Beijing's carbon emission reduction.

Road traffic is a key area of carbon emissions [9], and a large number of studies have calculated the carbon emissions of transportation. Fei Chen, Dajian Zhu, and Kun Xu (2009) quantified the total carbon emission of Shanghai traffic and the carbon emission of different modes of transportation through a low-carbon model [10]. In the study, the low-carbon recommendations for road traffic were given mainly from the perspective of changing urban space utilization. Boyang Gao and Weidong Liu (2013) set different emission reduction scenarios in which they showed the huge carbon emission reduction potential of road transportation to calculate carbon emissions. They suggested giving priority to the development of public transportation, encouraging the development of small-displacement vehicles, reducing vehicle energy consumption, and controlling emission standards to achieve road traffic energy saving and emission reduction [11]. Sun, Zhang, and Xue et al. (2017) designed and used the mobile monitoring system, estimated traffic carbon emissions by collecting traffic flow, meteorological conditions, and vehicular carbon emissions, and found that the arterial roads brought about 50\% of the road traffic carbon emissions [12]. In addition, Qing Zhang (2012), Yuguo Tao (2015), and Huihui Wang (2018) used the "bottom-up" method to calculate carbon emissions of regional road traffic [13-15]. Morrow, Gallagher, and Collantes et al. (2010) measured carbon dioxide emissions through a general equilibrium model, arguing that the current transport department policies could not achieve the goal of reducing greenhouse gas emissions to $14 \%$ in 2020 from 2005 in the U.S. [16]. 
Baixue Wang and Kun Guo (2018) studied the carbon emissions and the carbon emission reduction potential of buses and taxis based on the super-efficiency SBM (Slack Based Measure) model and ML (Malmquist-Luenberger) index. The research results showed that the carbon emission efficiency of Beijing buses was very high, but there was a significant downward trend. So, the operational efficiency needed to be improved in the future. The carbon emission efficiency of taxis in Beijing was very low, and technical investment should be increased to promote the process of upgrading [17]. Lixiang Zhao and Jing Tang (2018) used the Leap (Long-range Energy Alternatives Planning System) model with situational analysis to focus on the carbon emission reduction effect of Beijing passenger transportation energy improvement. The study considered that the short-term increase in fuel consumption limit standards had a good emission reduction effect, but in the long run, the use of clean energy vehicles for emission reduction would be more obvious [18].

Due to different research methods, there are different understandings of important factors affecting road traffic carbon emissions. Jia Wang and Shuli Ding (2013) used the factor analysis method and found that economic growth, population, passenger traffic volume, freight traffic volume, and private car ownership were the main factors affecting urban traffic carbon emissions [19]. Based on the STIRPAT (Stochastic Impacts by Regression on Population, Affluence, and Technology) theory model, Lin Pang (2017) selected population size, industrial structure, energy consumption structure, urbanization rate, GDP, energy utilization efficiency, passenger turnover volume, and freight turnover volume as explanatory variables to study the performance of carbon emissions [20]. Liang $\mathrm{Li}$ (2014) constructed an evaluation system for road carbon emissions, and explored the factors affecting carbon emissions from four perspectives: Energy efficiency, transport structure, work effect of energy saving and emission reduction, and trade policies [21]. Starting from the use of urban electric vehicles and new energy vehicles, Xiuyuan Zhang, Xinmiao Yang, and Yan Yan (2014) took vehicle speed, traffic infrastructure, load rate, and fuel type as the main parameters of emission measurement. They calculated the public energy consumption and carbon emission [22]. Jieping Han et al. (2012) used the statistical regression method to study the influencing factors affecting road traffic carbon emissions [23]. The passenger turnover and freight turnover were used as explanatory variables to construct the regression model, but the impact of traffic congestion on carbon emissions was not considered. Taoxin Zhang (2012) selected the urbanization rate, per capita GDP, urban residents' consumption level, and transportation energy intensity as the independent variables from three perspectives of urbanization, economic development, and technological progress, and took urban road traffic carbon emission as the dependent variable [24]. Then, the IPAT model was used to carry out statistical forecasting and situational analysis. Many studies have used the LMDI (Log-Mean Divisia Index) method to analyze the influencing factors and effects of road traffic carbon emissions. When studying the factors affecting transportation carbon emissions in Shanxi Province, Limin Yao (2016) adopted the LMDI method to decompose the carbon emission driving factors into energy structure, industrial structure, economic effects, and population size [25]. Kaiya Wu et al. (2012) used the LMDI decomposition method to decompose and analyze the changes in carbon emissions in Shanghai's transportation sector [26]. According to the IPCC (Intergovernmental Panel on Climate Change) guidelines for national greenhouse gas inventories and statistical yearbook energy consumption data, the carbon emission and carbon emission intensity of Shanghai's transportation industry were measured from 2000 to 2010. The study concluded that the energy structure had a weaker effect on the reduction of carbon intensity, but there was an increasing trend of population and GDP promoted carbon emissions. Wei et al. (2013) used the LMDI decomposition method to analyze the contribution of transportation structure optimization to carbon emission reduction in the transportation industry [27]. The research found that GDP per capita was the main driving factor for the increase of carbon emissions in the transportation industry, while the reduction of transportation intensity (the ratio of transport turnover to GDP, that is, the dependence of economic development on transportation) and energy consumption structure adjustment were the restraining factors. Based on the LMDI decomposition method, Yu Jie et al. (2015) decomposed the factors affecting carbon emission changes into six aspects: Transportation energy consumption 
structure, unit consumption level, transportation structure, transportation intensity, per capita GDP, and population [28].

Traffic congestion has brought about manys impacts. Pengjun Zhao and Hairong Wan (2016) and Hongjun Zhao and Suwei Feng (2015) explored the scheme of congestion control based on pollutions caused by traffic congestion $[29,30]$. Minghao Zhu (2013) used qualitative and quantitative methods to analyze the impact of traffic congestion on factors, such as energy consumption, land use, environmental pollution, residents' travel costs, and residents' travel time [31]. Existing research confirms the increase in carbon emissions from traffic congestion based on the relationship between fuel consumption and carbon emissions. Barth and Boriboonsomsin (2008) collected energy consumption data on the field through the energy and emission model, obtained the real-time traffic information by the traffic performance measurement system, and confirmed the increase in vehicle energy consumption caused by congestion [32]. They believed that congestion mitigation strategies, speed management techniques, and shock wave suppression techniques could reduce $20 \%$ of the carbon dioxide emissions for Southern California traffic. Jingrong Wang, He Xiao, and Jianguang Xie (2015) established a calculation model for traffic congestion carbon emissions [33]. They determined the model parameters through field investigation and analysis, and the calculation confirmed the increase of carbon emissions caused by congestion. According to the survey data of traffic conditions, Bin $\mathrm{Li}$ and Jun Zhou (2017) calculated the carbon emission during the traffic congestion period in a busy traffic direction at a certain intersection [34]. It was found that the carbon emissions of the traffic congestion period was four times that of normal time. Xiaohong Chen, Xiaonian Shan, and Jianhong Ye et al. (2017) used the motor vehicle emissions simulation (MOVES) method to simulate the changes in carbon emission of a feeder bus under different traffic congestion and passenger load [35]. Results showed that total fuel and emissions of a feeder bus during peak hours presented an increasing trend compared with the values during off-peak hours. In addition, the MOVES method was applied to indirectly verify the increase of carbon emissions caused by traffic congestion based on the research on the characteristic relationship between vehicle pollutant emission factors and speed. Bigazzi A (2011) [36,37] and Liu et al. (2013) [38] studied the driving conditions of regional roads. The parameters were corrected by MOVES software, and the characteristic relationship between the average vehicle speed and pollutant emission factor and the impact of congestion on carbon emissions were measured.

According to the above literature, many scholars have done a lot of research on traffic congestion and carbon emissions in regional road transportation. The existing research can be summarized into three aspects: The impact factors of road traffic carbon emissions, the calculation of road traffic carbon emissions, and the carbon emissions of regional road traffic under congested conditions.

The factors affecting the carbon emissions of road traffic cover economic development, energy structure, industrial structure, population size, vehicle scale, urbanization development, and the main business of road transportation. Different analysis methods of the factors affecting the road traffic carbon emission brings certain differences to factors' selection. However, GDP, population, vehicle ownership, main business volume of road traffic, and traffic energy intensity are all widely considered and recognized influencing factors. However, the choice of factors varies according to the region, model, and research objectives, so the selection method cannot be generalized.

Based on the vehicle mileage and one-hundred-kilometer fuel consumption, the carbon emissions of road traffic can be measured. Such methods can be used to directly calculate carbon emissions, but the disadvantages are the data collection difficulty and huge data amount. In terms of model selection, the general equilibrium model, the super-efficient SBM model, and the LEAP model can be used for measurement. The research achievements of road traffic carbon emission calculations lay the foundation for this study.

The existing studies calculated the carbon emission of road traffic caused by traffic congestion in different situations from the perspective of transportation fuel consumption and carbon emissions. There is a lack of research considering the extent to which traffic congestion affects carbon emissions, that is, that quantify the impact of different degrees of traffic congestion on carbon emissions. 
In addition, with the increasing popularity of the low-carbon concept, the equilibrium between a low-carbon economy and traffic congestion has become a constraint to solve other problems. However, little literature on the low carbon and traffic congestion exists at present as well. Moreover, there are few studies using economic models to study the equilibrium between road traffic congestion and a low-carbon economy. Therefore, this paper attempts to use economic models to solve the problem of equilibrium between traffic congestion and a low-carbon economy.

This paper aims to find a balance between traffic congestion and a low-carbon economy by establishing an equilibrium model to provide guidance on carbon emission reduction of road traffic in Beijing and other regions. Therefore, the purposes of this study are as follows: (1) Select carbon emission influence factors and traffic congestion quantitative indicators; (2) establish the equilibrium model between road traffic congestion and a low-carbon economy; and (3) discuss whether Beijing can achieve this equilibrium or not.

\section{Materials and Methods}

\subsection{Regression Model of Carbon Emission in Traffic Congestion}

\subsubsection{Selection of Carbon Emission Influence Factors and Data Sources}

(1) Beijing road traffic carbon emission (C)

The lack of data on road traffic carbon emissions in Beijing requires reasonable calculation of road traffic carbon emissions. This paper calculates carbon emissions based on a method in the 2006 IPCC Guidelines for National Greenhouse Gas Inventories (IPCC 2006) [39]. Carbon emissions are multiplied by the fuel consumption data of regional traffic and the carbon emission coefficient of each energy. The calculation formula is as follows:

$$
C=\sum E_{i} \times F_{i} \times K_{i}
$$

$C$ is the Beijing road traffic carbon emissions.

$E_{i}$ is the $i$ energy consumption.

$F_{i}$ is the conversion coefficient of $i$ energy into standard coal.

$K_{i}$ is the carbon emission coefficient of a unit standard coal of $i$ energy.

According to the research on China's carbon dioxide emissions by Bofeng Cai, Dong Cao, and Lancui Liu et al. (2011), the carbon emissions of road traffic accounted for $85 \%$ of the total carbon emissions in the transportation, storage, and postal trade [9]. According to the consumption of all kinds of energy in the trade, the annual road traffic carbon emissions can be calculated. Therefore, the road traffic energy consumption in formula (1) can be replaced by the total energy consumption in transportation, storage, and postal trade.

According to the data of the 2008-2017 Beijing statistical yearbook, the energy used in transportation, storage, and postal trade (the road traffic energy usage is counted in the whole trade in the Beijing statistical yearbook) includes coal, gasoline, kerosene, diesel oil, fuel oil, liquefied petroleum gas (LPG), natural gas (NG, including liquefied natural gas), heat, and electricity. The energy consumption data are shown in Table 1, and the conversion coefficient and emission coefficient are shown in Table 2. Among them, 137.3 thousand tons of liquefied natural gas were used in 2016, which is converted into natural gas for calculation. 
Table 1. Energy usage in the transportation, warehousing, and postal trade.

\begin{tabular}{|c|c|c|c|c|c|c|c|c|c|}
\hline Year & $\begin{array}{c}\text { Coal } \\
\left(10^{4} t\right)\end{array}$ & $\begin{array}{c}\text { Gasoline } \\
\left(10^{4} t\right)\end{array}$ & $\begin{array}{c}\text { Kerosene } \\
\quad\left(10^{4} t\right)\end{array}$ & $\begin{array}{c}\text { Diesel } \\
\text { Oil }\left(10^{4} t\right)\end{array}$ & $\begin{array}{c}\text { Fuel Oil } \\
\left(10^{4} t\right)\end{array}$ & $\begin{array}{l}\text { LPG } \\
\left(10^{4} t\right)\end{array}$ & $\begin{array}{c}\text { NG } \\
\left(10^{8} \mathrm{~m}^{3}\right)\end{array}$ & $\begin{array}{c}\text { Heat } \\
\left(10^{10} \mathrm{~kJ}\right)\end{array}$ & $\begin{array}{c}\text { Electric } \\
\left(10^{8} \mathrm{~kW} \cdot \mathrm{h}\right)\end{array}$ \\
\hline 2007 & 27.29 & 52.57 & 276.55 & 102.66 & 0 & 0.64 & 4.66 & 508.44 & 34.84 \\
\hline 2008 & 26.89 & 46.42 & 317.83 & 128.61 & 0.14 & 0.59 & 5.90 & 963.53 & 44.84 \\
\hline 2009 & 25.15 & 43.68 & 341.45 & 128.76 & 0.13 & 0.55 & 6.47 & 582.45 & 49.24 \\
\hline 2010 & 20.29 & 41.04 & 392.15 & 127.27 & 0.20 & 0.44 & 6.71 & 667.89 & 50.37 \\
\hline 2011 & 18.00 & 44.99 & 419.35 & 133.88 & 1.15 & 0.34 & 2.38 & 689.70 & 61.96 \\
\hline 2012 & 15.86 & 44.03 & 442.79 & 117.34 & 1.28 & 0.34 & 8.22 & 663.38 & 69.11 \\
\hline 2013 & 15.94 & 45.40 & 476.51 & 124.28 & 1.60 & 0.35 & 2.35 & 603.86 & 44.64 \\
\hline 2014 & 16.09 & 46.45 & 507.07 & 126.56 & 1.88 & 0.32 & 3.17 & 615.33 & 45.02 \\
\hline 2015 & 12.36 & 44.65 & 543.78 & 1180 & 1.97 & 0.38 & 2.11 & 594.20 & 47.31 \\
\hline 2016 & 7.99 & 41.62 & 593.66 & 109.92 & 1.49 & 0.28 & 3.88 & 538.60 & 50.61 \\
\hline
\end{tabular}

Data source: Beijing Statistical Yearbook (The table is compiled by authors.).

Table 2. Conversion coefficient and carbon emission coefficient.

\begin{tabular}{|c|c|c|c|c|c|c|c|c|c|}
\hline Energy & Coal & Gasoline & Kerosene & Diesel Oil & Fuel Oil & LPG & NG & Heat & Electric \\
\hline $\begin{array}{c}\text { Conversion } \\
\text { coefficient } \\
\text { Unit }\end{array}$ & $\begin{array}{l}0.7143 \\
\text { tec } / \mathrm{t}\end{array}$ & $\begin{array}{l}1.4714 \\
\text { tec/t }\end{array}$ & $\begin{array}{l}1.4714 \\
\text { tec } / \mathrm{t}\end{array}$ & $\begin{array}{l}1.4571 \\
\text { tec } / \mathrm{t}\end{array}$ & $\begin{array}{l}1.4286 \\
\text { tec } / \mathrm{t}\end{array}$ & $\begin{array}{l}1.7143 \\
\text { tec } / \mathrm{t}\end{array}$ & $\begin{array}{c}13.3 \\
\text { tec } / 10^{4} \mathrm{~m}^{3}\end{array}$ & $\begin{array}{c}0.03412 \\
\text { tec } / 10^{6} \mathrm{~kJ}\end{array}$ & $\begin{array}{c}1.229 \\
\text { tec } / 10^{4} \mathrm{~kW} \cdot \mathrm{h}\end{array}$ \\
\hline $\begin{array}{c}\text { Carbon emission } \\
\text { coefficient }\end{array}$ & 0.7559 & 0.5538 & 0.5714 & 0.5921 & 0.6185 & 0.5042 & 0.4483 & 0.67 & 0.6036 \\
\hline
\end{tabular}

The unit of carbon emission coefficient is t carbon/tec. Data source: Beijing Statistical Yearbook (The table is compiled by authors.).

(2) Traffic index (TI)

Traffic congestion has brought great inconvenience to the road traffic in Beijing, which has seriously affected the traffic efficiency. It causes vehicles to spend more time on the road, start and stop more frequently, and increase energy consumption and carbon emissions. Therefore, the traffic index was selected as the explanatory variable.

The traffic index is the abbreviation of the road traffic operation index (also called the road traffic congestion index), and the road traffic operation index is an indicator that comprehensively reflects the road network traffic operation status. The value ranges from 0 to 10 and is divided into five levels. Among them, 0 2, 2 4, 4 6, 6 8, and 8 10 correspond to five levels of "unblocked", "basic smooth", "lightly congested", "moderately congested", and "seriously congested". The higher the value, the more serious the traffic congestion situation. With regard to the calculation method, the traffic index is obtained by in-depth processing of dynamic vehicle position information (referred to as floating car data) distributed in urban streets and lanes, and the floating car data is transmitted back to the data processing center in real time through the communication network. The specific data processing and calculation process is as follows: First, the vehicle position data is processed to obtain the average running speed of the vehicles in different functional level roads. Then, according to the different road functions and the traffic data, the weight of the road in the whole network is calculated. Finally, through the human perception of congestion, the index value is converted to $0-10$.

Beijing established the Beijing Transport Institute in 2002, and began to publish the Beijing real time traffic index in 2007. Until now, the statistics of the 2007-2016 total 10 years can be obtained on the website of the Beijing Transportation Institute.

\section{(3) Gross Domestic Product (GDP)}

GDP is usually used to measure the economic situation of a country (or region). Economic development has an obvious positive correlation with energy consumption and carbon emissions. Therefore, the Beijing GDP and the GDP of transportation, storage, and postal trade (trade GDP) were selected as explanatory variables. Relevant data were obtained from the website of the National Bureau of Statistics of the People's Republic of China.

(4) Permanent resident population (PRP) 
The growth of the permanent resident population will inevitably lead to the growth of traffic volume and energy consumption. At present, China's energy consumption structure based on fossil energy makes the population growth necessarily lead to the growth of carbon emissions, so the urban population was considered as an explanatory variable. The data on the permanent resident population also comes from the website of the National Bureau of Statistics of the People's Republic of China.

\section{(5) Passenger and freight statistical data}

The main business of road transport is the transportation of passengers and goods. It is generally believed that the higher the volume of business and the energy consumption, the more carbon emissions will be generated. So, the road passenger traffic volume (PTV), road freight traffic volume (FTV), turnover of passenger traffic (TPT), and turnover of freight traffic (TFT) in Beijing statistical yearbook were selected as explanatory variables.

(6) Possession of civil vehicles (PCV)

In recent years, the number of civil vehicles in Beijing has been increasing rapidly. The increase of cars leads to an increase of carbon emissions from road traffic, so the number of civil cars was selected as an explanatory variable.

Electric vehicles (EV) have a high energy efficiency and use clean electricity. However, EV was not selected as an explanatory variable. There are two reasons. First, the scale effect of Beijing EVs has not formed. By June 2018, the number of EVs in Beijing was 175,000, which only reached 3\% of the total civil vehicles in 2016 (5484 thousand cars kept in Beijing in 2016, Table 3) (Beijing Daily 2018) [40]. Second, in view of the current energy structure, EVs only divert carbon emissions, but whether they really reduce carbon emissions has not been decided.

The introduction mentions that since 2017, Beijing has handled 725,000 traffic permits for vehicles to Beijing per week on average. That is to say, an average of about 104,000 out-of-city vehicles go into Beijing every day. Temporary Beijing vehicles will also bring traffic congestion and carbon emissions, but the number of these vehicles only accounts for $1.8 \%$ of the total civil vehicles in 2016 , which is also not considered in this model.

The data on the possession of civil vehicles is all from the website of the Ministry of Transport of the People's Republic of China.

(7) Sample data summary

Because there are only 10 years traffic index data, the explanatory variables and the explained variable were selected from 2007 to 2016, as shown in Table A1.

\subsubsection{Multivariate Nonlinear Regression Model for Road Traffic Carbon Emission}

Road traffic carbon emissions are affected by many factors, but the quantitative relationship between the factors and carbon emissions is difficult to determine. Multivariate regression analysis can be used to determine the quantitative relationship between variables, build quantitative models, and make predictions.

The purpose was to build a regression model to find out the factors that have a significant impact on carbon emissions and to build a reasonable equation to quantify the impact of the factors on carbon emissions. In this process, we tested whether traffic congestion has a significant impact on carbon emissions, and identify factors that have a significant impact on road traffic carbon emissions.

The explained variable of the regression model is $Y_{t}$, and $t=1,2 \ldots T$ represents time. $X_{i t}$ is the explanatory variable or the elementary function variation of the explanatory variable, $i=1,2 \ldots N$ represents different ones. $\alpha_{t}$ is a constant term, $\beta_{i t}$ is the partial regression coefficient, $\mu_{t}$ is random error. The regression model can simply be expressed as formula (2):

$$
Y_{t}=\alpha_{t}+\sum_{i=1}^{N} \beta_{i t} X_{i t}+\mu_{t}
$$




\subsection{The Equilibrium Model between Road Traffic Congestion and Low-Carbon Economy}

The equilibrium between traffic congestion and a low-carbon economy means that the carbon emission regression model and carbon emission constraint form an equation. That is:

$$
C_{t}=Y_{t}=\alpha_{t}+\sum_{i=1}^{N} \beta_{i t} X_{i t}+\mu_{t}
$$

To predict and design traffic congestion and other explanatory variables, we can get other variables' values through the equilibrium equation, and then analyze and discuss the equilibrium results.

\subsection{Beijing Traffic Carbon Emission Intensity under the Limit of Low-Carbon Economy}

On September 2015, Chinese President Jinping Xi reiterated that China aimed to achieve a $40 \%-45 \%$ reduction in carbon emission intensity in 2020 than in 2005 at the meeting of the United Nations Conference on climate change leaders' working conference in the United Nations Headquarters, New York. This is the target of our low-carbon economy limit.

The formula for calculating the emission intensity, $A_{t}$, in transportation, storage, and postal trade is:

$$
A_{t}=\frac{\operatorname{tradeC}_{t}}{\operatorname{tradeGDP}}
$$

trade $C_{t}$ is the carbon emissions in transportation, storage, and postal trade; and tradeGDP $P_{t}$ is the GDP of transportation, storage, and postal trade.

Carbon emission intensity of unit GDP in transportation, storage, and postal trade is applied to simulate the road traffic carbon emission intensity. According to the Beijing statistical yearbook, the energy used by Beijing in transportation, storage, and postal trade in 2005 and 2016 is shown in Table 3:

\begin{tabular}{|c|c|c|c|c|c|c|c|c|c|}
\hline Year & $\begin{array}{c}\text { Coal } \\
\left(10^{4} t\right)\end{array}$ & $\begin{array}{l}\text { Gasoline } \\
\left(10^{4} t\right)\end{array}$ & $\begin{array}{c}\text { Kerosene } \\
\left(10^{4} t\right)\end{array}$ & $\begin{array}{c}\text { Diesel } \\
\text { Oil }\left(10^{4} \mathbf{t}\right)\end{array}$ & $\begin{array}{l}\text { Fuel Oil } \\
\left(10^{4} t\right)\end{array}$ & $\begin{array}{c}\text { LPG } \\
\left(10^{4} t\right)\end{array}$ & $\begin{array}{c}\mathrm{NG} \\
\left(10^{8} \mathrm{~m}^{3}\right)\end{array}$ & $\begin{array}{c}\text { Heat } \\
\left(10^{10} \mathrm{~kJ}\right)\end{array}$ & $\begin{array}{c}\text { Electric } \\
\left(10^{8} \mathrm{~kW} \cdot \mathrm{h}\right)\end{array}$ \\
\hline 2005 & 22.89 & 48.46 & 189.04 & 56.55 & 0 & 0.72 & 3.51 & 550.68 & 13.96 \\
\hline
\end{tabular}

Table 3. Beijing 2005 and 2016 energy used in transportation, warehousing, and postal trade.

Data source: Beijing Statistical Yearbook (the table was compiled by authors).

According to the carbon emission calculation formula (1), the carbon emission of transportation, storage, and postal trade in 2005 and 2016 can be calculated. Additionally, formula (4) can be used to calculate the carbon emission intensity of transportation, storage, and postal trade in 2005 and 2016. Based on the carbon emission intensity in 2005 and the target of reducing carbon emission intensity by $45 \%$, the target carbon emission intensity in 2020 was calculated.

Based on the data of 2016, we calculated the reduction of the carbon emission intensity in 2017-2020 to achieve the goal of carbon emission intensity in 2020. Assuming that the annual carbon emission intensity is reduced at the same rate in 4 years, $A_{2016}$ represents the actual carbon emission intensity in 2016, and $A_{2020}$ represents the target carbon emission intensity in 2020. The annual reduction of carbon emission intensity, $\sigma$, in 2017-2020 is:

$$
\sigma=1-\sqrt[2020-2016]{A_{2020} / A_{2016}}
$$




\section{Results}

\subsection{Carbon Emission Regression Model and Hypothesis Test}

\subsubsection{Stepwise Regression and Screening of Influential Factors}

Linear stepwise regression was performed on the data in Table A1 using SPSS software. All the explanatory and explained variables were placed in the model for the model significance test and partial regression coefficient significance test. The partial regression coefficients that did not meet the significance test were eliminated. The explanatory variables that ultimately satisfied the test include the gross domestic product (GDP), road passenger traffic volume (PTV), and traffic index (TI). In the process, we focused on adjusting the functional relationship between the traffic index representing the degree of congestion and carbon emissions, then participated in the linear stepwise regression. After collecting the actual data, the research team first conducted linear regression simulation, but found that the results did not agree with the actual, linear model and did not reflect the relationship between variables very well.

According to the scatter plot and experience, the relationship between the two must be nonlinear. With the aggravation of traffic congestion, its carbon emissions will accelerate. Figure 1 shows the scatter plot between $C$ (carbon emissions from road traffic) and 1/TI (the reciprocal of the traffic index) after eliminating the effects of GDP and PTV from C. A line was basically synthesized.

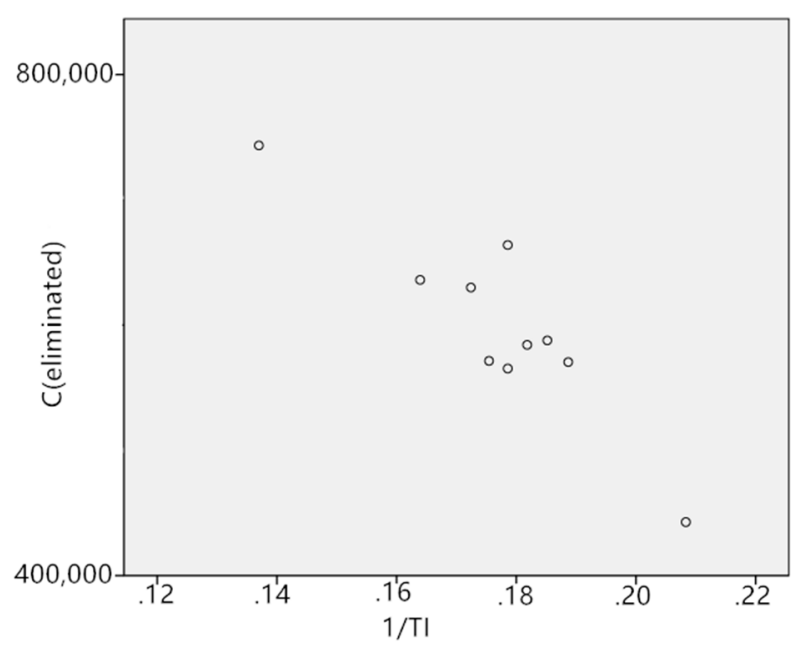

Figure 1. Scatter plot of C (eliminated) and 1/TI.

\subsubsection{Multivariate Nonlinear Regression Model}

Therefore, based on the multivariate linear regression model research, and through testing and observing the fitness of different nonlinear function relations, the multivariate nonlinear regression model was constructed to simulate the most appropriate quantitative relationship.

The results of the SPSS regression operation are shown in Table 4 . Thus, under the 5\% significant level, the regression model equation is:

$$
\hat{C}=2897175.270+137.824 G D P+5.461 P T V-3738207.848 \frac{1}{T I},
$$

$\hat{C}$ is the Beijing traffic carbon emissions;

$G D P$ is the Beijing gross domestic product;

$P T V$ is the Beijing road passenger traffic volume; and

$T I$ is the Beijing traffic index. 
Table 4. Coefficients, significance test, and collinearity statistics.

\begin{tabular}{cccccccc}
\hline Model & Unstandardized Coefficients & $\begin{array}{c}\text { Standardized } \\
\text { Coefficients }\end{array}$ & $\mathbf{t}$ & Sig. & \multicolumn{2}{c}{ Collinearity Statistics } \\
\hline & B & Std. Error & Beta & & & Tolerance & VIF \\
\hline (Constant) & $2,897,175.270$ & $156,938.494$ & & 18.461 & 0.000 & & \\
GDP & 137.824 & 3.713 & 1.114 & 37.117 & 0.000 & 0.435 & 2.301 \\
PTV & 5.461 & 0.498 & 0.377 & 10.958 & 0.000 & 0.330 & 3.026 \\
1/TI & $-3,738,207.848$ & $1,268,004.322$ & -0.103 & -2.948 & 0.026 & 0.318 & 3.144 \\
\hline
\end{tabular}

\subsubsection{Model Hypothesis Test Results}

After the SPSS stepwise regression results, the statistical significance and economical significance test were needed. The regression estimator is only meaningful when the model satisfies many basic assumptions, so that the regression model can be used to predict. First, the model classic hypothesis tests (residual error heteroscedasticity test, serially correlated D-W statistic test, and collinearity diagnosis) were examined to determine whether the regression model could be adopted. Then, at $5 \%$ significant levels, the goodness of fit and the significant F statistic of the model were examined. On the condition of a good fit and an acceptable F test, the results of the statistics test of partial regression coefficient were examined to judge the statistical rationality of the regression equation. Finally, the economic significance of the regression model was tested to judge whether the influence of the explanatory variables on the explained variables conforms to the expectation, and to judge the correctness of the regression model.

(1) Heteroscedasticity test

If there is heteroscedasticity in a regression model, the model is invalid and must be corrected, thus the heteroscedasticity test of random error was necessary.

The results can be seen from Figures 2 and 3 that the regression standardized residual is basically in the normal distribution with a mean of 0 , and the normal P-P plot of regression standardized residual is basically fitted into a straight line. So, the random error can be considered to have no heteroscedasticity.



Figure 2. Heteroscedasticity test: Regression standardized residual. 


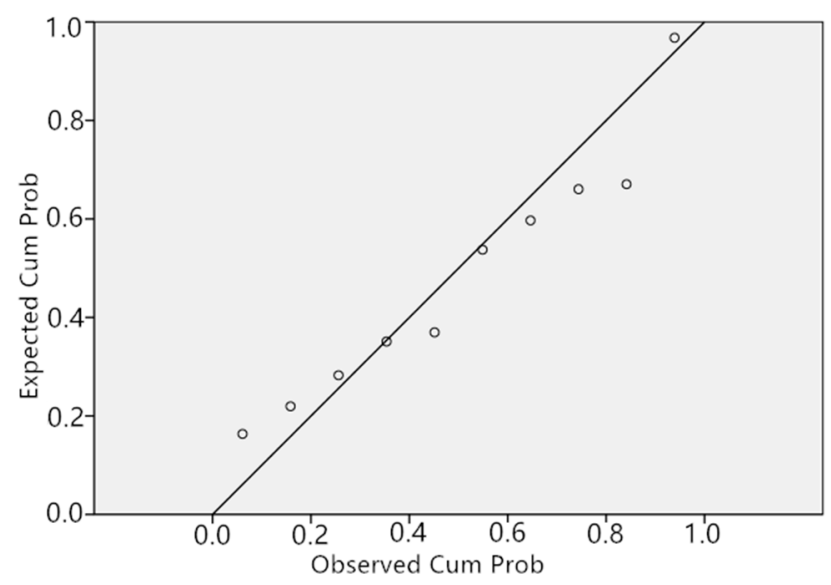

Figure 3. Heteroscedasticity test: Normal P-P plot of regression standardized residual.

\section{(2) Serially correlated test}

An investigation of the serially correlation of explanatory variables is one of the basic conditions to ensure the availability of models. The most commonly used test is the D-W test. The test requires that the model has a constant term, the explanatory variables are not random, the lagged variable is not used as the explanatory variable, and the sample data is not missing according to the time series.

The above conditions were consistent with the model. The number of explanatory variables in the model was 3, and the number of samples was 10 . In this case, the D-W value should be considered in the interval $(1.66,2.267)$ without a sequence correlation. As shown in Table 6, the D-W statistic of the model was 2.256 , which was verified by testing.

\section{(3) Collinearity test}

Within regression, there inevitably exists the problem of collinearity among explanatory variables. If serious, the partial regression coefficient cannot be determined, and the standard error tends to infinity. The value of the variance inflation factor, VIF, can be used to judge the degree of collinearity.

When VIF is in the interval $(0,10)$, there is basically no collinearity among explanatory variables. As shown in Table 4, VIF $F_{G D P}=2.301, V I F_{P T V}=3.026, V I F_{1 / T I}=3.144$, all passed the test.

\section{(4) Regression equation significance test}

By means of variance analysis, the quantity relationship between explanatory variables and explained variables in the model was judged. The form of the regression equation significance test is as follows:

$$
\begin{gathered}
\text { For } Y_{t}=\alpha_{t}+\sum_{i=1}^{N} \beta_{i t} X_{i t}+\mu_{t}, \\
H_{0}: \alpha=0, \beta_{i}=0, \\
H_{1}: \alpha, \beta_{i} \text { are not completely zero. }
\end{gathered}
$$

The basis for determining whether the hypothesis test was established is the F statistic and the corresponding significance level of the regression model. As can be seen from Table 5, the level of significance was close to 0 and less than 0.05 . The equation refutes the original hypothesis. Th regression model constant term and partial regression coefficient were not all zero. That is, the regression model is acceptable under the significant level of the default $5 \%$. 
Table 5. Regression equation significance test.

\begin{tabular}{cccccc}
\hline Model & Sum of Squares & df & Mean Square & F & Sig. \\
\hline Regression & $3,917,427,528,659.430$ & 3 & $1,305,809,176,219.810$ & 848.718 & 0.000 \\
Residual & $9,231,398,469.145$ & 6 & $1,538,566,411.524$ & & \\
Total & $3,926,658,927,128.580$ & 9 & & & \\
\hline
\end{tabular}

\section{(5) Coefficient significance test}

The overall significance of the equation does not mean that every explanatory variable has a significant influence on the explanatory variables. It is necessary to test every explanatory variable and determine whether they can be retained in the model. The hypothesis test is:

$$
\begin{gathered}
\text { For } Y_{t}=\alpha_{t}+\sum_{i=1}^{N} \beta_{i t} X_{i t}+\mu_{t}, \\
H_{0}: \beta_{i}=0, \\
H_{1}: \beta_{i} \neq 0 .
\end{gathered}
$$

The basis of judging whether the hypothesis test was established is the $t$ statistic of partial regression coefficient and the corresponding significant level. It can be seen from Table 5 that the GDP, PVT and 1/TI were selected as explanatory variables of the regression model. The significant level of the GDP, PTV, and 1/TI were all less than 0.05 . Thus, under the $5 \%$ significant level, the influence of the explanatory variables on the explained variables was significant.

(6) Goodness of fit test

The closer the $\mathrm{R}$ square and adjusted $\mathrm{R}$ square are to 1 , the better the fitting degree of the regression line to the sample observations is. It can be seen from $R$ square and adjusted $R$ square that the regression equation was very well fitted, as shown in Table 6.

Table 6. Goodness of fit test and serially correlated test.

\begin{tabular}{ccccc}
\hline $\mathbf{R}$ & $\mathbf{R}$ Square & Adjusted R Square & Std. Error of the Estimate & Durbin-Watson \\
\hline $\mathbf{0 . 9 9 9}$ & 0.998 & 0.996 & $39,224.56388$ & 2.256 \\
\hline
\end{tabular}

\section{(7) Economic significance test}

The test of economic significance is to check whether the symbols of regression coefficients are consistent with expectations. According to the positive and negative coefficients and the standardized coefficients of the partial regression coefficients, we can see:

As the most important factor affecting the carbon emission in the regression equation, the normalized coefficient of GDP was 1.114, which means that the growth of GDP leads to the growth of carbon emissions. It is reasonable for the current Beijing road traffic to use fossil energy as the main energy source.

The standardized coefficient of PTV was 0.377, which indicates that the influence degree is not greater than GDP. It was positively related to the growth of carbon emissions. The growth of business leads to rational energy consumption and carbon emission growth.

$1 / \mathrm{TI}$, which is the reciprocal of the traffic index, had a standardized coefficient of -0.103 , indicating that $1 / \mathrm{TI}$ has a negative correlation with road traffic carbon emissions. This shows that in cities with a small proportion of electric vehicles, the increase in congestion will increase carbon emissions, which conforms with the opinions of Jingrong Wang (2015) [33] and Bin Li (2017) [34]. In theory, the nonlinear relationship between TI and road traffic carbon emissions may be due to traffic congestion causing a reduction in road passenger traffic volume (PTV). The traffic index is a comprehensive indicator covering the vehicle density and the average vehicle speed. Therefore, 
non-linearity may also be caused by the variability in the traffic flow (ration of light and heavy vehicles, transit traffic load, etc.). 1/TI played a role in correcting the model. Next, according to the regression model of Equation (6), a functional image between the carbon emission reduction and the traffic index was simulated, as shown in Figure 4. It can be seen from the function image that within a certain range of values, as the unit traffic index decreases, the carbon emission reduction of road traffic accelerates.

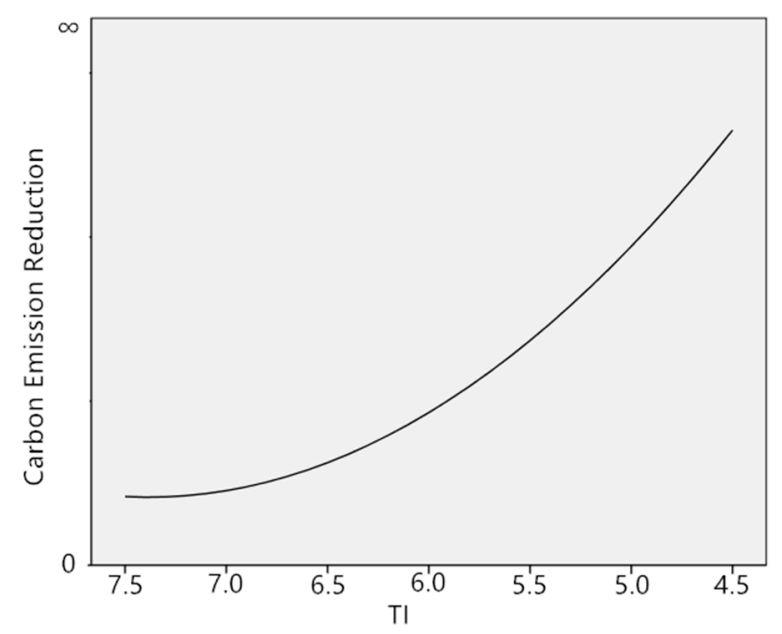

Figure 4. Trend of carbon emission reduction varying with TI.

\subsection{Traffic Congestion and Low-Carbon Economy Equilibrium Analysis}

\subsubsection{The Equilibrium Model of Traffic Congestion and a Low-Carbon Economy}

The equilibrium between traffic congestion and a low-carbon economy is the equilibrium between the road traffic carbon emission target and the prediction of carbon emissions from the regression equation. The equilibrium equation is:

$$
C=2897175.270+137.824 G D P+5.461 P T V-3738207.848 \frac{1}{T I}
$$

$C$ is the road traffic carbon emissions under the constraint of a low-carbon economy. GDP, PTV, and TI represent the Beijing GDP, road passenger traffic volume, and traffic index, respectively.

\subsubsection{Upper Limit of the Carbon Emission Intensity}

According to the formula of carbon emissions (2), the carbon emissions of transportation, storage, and post trade in 2005 was $C_{2005}=3040676.820$ tons, tradeGDP $P_{2005}=40.47$ billion yuan. In 2016, $C_{2016}=7067353.577$ tons, tradeGDP $P_{2016}=106.10$ billion yuan.

According to formula (3), the carbon emission intensity of the trade in 2005 was about $A_{2005}=$ 75.134 tons/million yuan, and in 2016, it was $A_{2016}=66.610$ tons/million yuan. Therefore, from 2005 to 2016 , Beijing transportation, storage, and postal trade actually reduced the carbon emission intensity by about $11.3 \%$. To achieve the $45 \%$ emission reduction target in 2020 , more than a $33.7 \%$ reduction is needed.

To achieve the goal of reducing by $45 \%$ in 2020, the upper limit of carbon the emission intensity in 2020 was calculated to be 41.324 tons/million yuan. According to formula (4), in 2017-2020, the annual carbon emission intensity should be reduced to $\sigma=1-\sqrt[2020-2016]{0.41324 / 0.66610} \approx 11.25 \%$.

\subsubsection{Equilibrium Scenarios Analysis}

(1) The change of traffic index under the limit of carbon emission intensity 
Based on 2016, the four years' carbon emission upper limit of 2017-2020 was predicted according to the carbon emission limit. The reasonable growth forecast of GDP and PTV was given. Thus, the change of the traffic index was obtained.

According to the draft of the Beijing "13th Five-Year" plan, the average growth rate of the GDP in Beijing will remain at 6.5\% in 2016-2020, keeping pace with the national GDP growth, slightly lower than that of the country.

To achieve a 45\% reduction in carbon emission intensity in 2020 than in 2005, carbon emission intensity should decrease by about $11.25 \%$ per year from 2016, assuming that the GDP of transportation, warehousing, and postal trade is consistent with the growth of GDP in Beijing so the upper limit of expected carbon emission can be estimated.

The Beijing PTV is in the face of a downward trend, affected by an increasing high-speed rail, air passenger volume, and private cars. As can be seen from Table 3, PTV has been in a declining state since 2012. So, we can assume that PTV will maintain a gradual reduction in 2017-2020. Here, we chose a decline of $80 \%$ per year (which is unlikely to be so exaggerated) to narrow the range of TI's change.

The equilibrium results are shown in Table A2. It can be seen that, in the case of maintaining an annual $6.5 \%$ GDP growth and continuously reducing PTV, it is still necessary to significantly reduce TI to achieve the target of carbon emission reduction. To achieve equilibrium, the TI of 2017 is reduced to 3.6, which means roads are basically open with only a little congestion. After 2018, the congestion index is close to or even below 2, that is, there is almost no road congestion, and all vehicles can be driven according to the road speed limit standards. It should be too difficult to achieve for Beijing's existing vehicle ownership.

(2) Change of carbon emission intensity under reasonable expectation

Based on the reasonable expectations of GDP, TI, and PTV from 2016, the change of carbon emission intensity during the 2017-2020 years was calculated.

Beijing GDP will grow steadily by $6.5 \%$. The change of PTV was not easy to determine, but the trend of an overall slow decline is the most reasonable. According to traffic development and the construction plan of Beijing during the "13th Five-Year" period, the TI should be controlled under 6 in 2017-2020.

From the 10 year data (Figure 5), we can see that there are three peaks in the Beijing traffic index, 2007, 2010, and 2015. Corresponding to each peak, Beijing implemented targeted policies to ease traffic congestion. After 2007, the policies of no driving for a whole day every week and restricting the use of private vehicles based on even- and odd-numbered license plates were implemented. In 2010, the policies of vehicle registrations via a lottery and parking fee adjustment were implemented. Removing the non-capital function policy was implemented in 2015. So, it is predicted that in 2017-2020, with the growth of vehicles in Beijing, TI will continue to maintain a small increase of under 6 . 


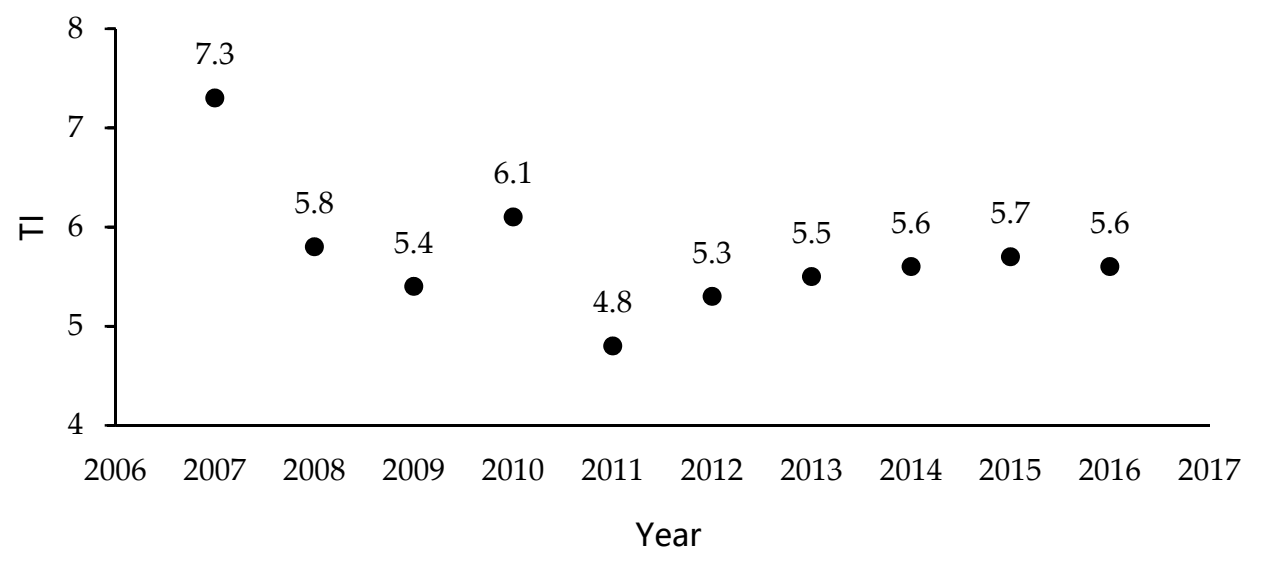

Figure 5. Beijing traffic index.

In a designed equilibrium scenario, we can reasonably estimate changes in carbon emissions and carbon intensity (Table A3).

It can be seen that carbon emissions will inevitably grow, from about 6.01 million tons in 2016 to about 7.00 million tons in 2020. In 2020, the carbon emission intensity is expected to be about 60.313 tons/million yuan, $80.3 \%$ of the carbon emission intensity in 2005. Carbon emission intensity will only reduce by $19.7 \%$, far from the target of $40 \%-45 \%$.

\section{Discussion}

In summary, the achievements in this paper are as following:

(1) GDP, PTV, and TI were selected as the influencing factors of road traffic carbon emissions.

(2) The regression model established reflects the extent to which traffic congestion affects carbon emissions. Both GDP and PTV were positively correlated with carbon emissions, and 1/TI was negatively correlated with carbon emissions. Additionally, within a certain range, as TI decreases, the rate of reduction of carbon emissions accelerates.

(3) An equilibrium model of traffic congestion and low-carbon economy was established. Through equilibrium scenario analysis, it was found that Beijing cannot achieve the equilibrium of a low-carbon economy and traffic congestion under the established carbon emission reduction target. Equilibrium can be achieved when the traffic index is close to or even below 2 or Beijing's traffic carbon reduction target is adjusted from the original $40 \%-45 \%$ to $19.7 \%$.

This paper compares the similarities and differences of the above achievements with the existing literature research and analyzes the reasons.

\subsection{Influencing Factors}

The factors involved in the stepwise regression of the model include FTV, PTV, TPT, TFT, GDP, PCV, PRP, and TI. By stepwise regression and test, three explanatory variables, GDP, PTV, and TI, were left.

Jieping Han (2012) [23] used empirical methods to select factors, such as population, GDP, PCV, TPT, and TFT, as independent variables. Based on the STIRPAT theoretical model, Lin Pang (2017) [20] selected the population size, industrial structure, energy consumption structure, urbanization rate, GDP, energy use efficiency, PTV, and FTV as independent variables. Taoxin Zhang (2012) [24] made a qualitative analysis from the perspectives of urbanization, economic development, and technological progress. He selected the urbanization rate, per capita GDP, urban residents' consumption level, and transportation energy intensity as independent variables. It can be seen from the above that whether they used empirical methods or quantitative model methods, they all chose the GDP as the influencing factor of traffic carbon emissions. Under the current energy structure dominated by fossil 
energy, the role of GDP growth in promoting carbon emissions has become a recognized phenomenon. Han Jieping (2012) [23] and Lin Pang (2017) [20] also selected the passenger turnover. However, they did not consider factors affecting traffic congestion.

Traffic congestion causes vehicles to accelerate and decelerate frequently, and it is difficult to maintain low energy consumption and high speed driving, resulting in increased fuel consumption. At the current stage of less than 3\% of electric vehicles in Beijing, traffic congestion will lead to an increase in traffic carbon emissions.

In terms of the selection of quantitative indicators of the congestion degree, Junfeng Wang (2017) chose traffic density as a variable. Traffic density refers to the number of registered civilian vehicles existing on the unit road area in urban areas, expressed in vehicles/10,000 $\mathrm{m}^{2}$ [41]. Cuicui Xiao et al. used the average vehicle speed index to represent traffic congestion. The traffic index is a comprehensive indicator of vehicle density and travel speed in the area [42]. It can comprehensively reflect the congestion situation. Therefore, this study considered the traffic index representing the degree of traffic congestion, which is an innovation point. However, there is no unified standard for reflecting congestion. The research results obtained according to different indicators have rationality. Therefore, when conducting traffic congestion and carbon emission research, the corresponding parameters reflecting traffic congestion should be selected according to different research purposes in different regions.

\subsection{Regression Model}

From the scientific and reasonable angle of the model design, the regression model was well fitted to the relationship between carbon emissions and the GDP, road passenger traffic volume, and TI. It conforms to the practical economic significance, and smoothly underwent a series of tests. It is believed that the model can commendably predict the Beijing road traffic carbon emissions in 2017-2020.

This paper constructed a nonlinear multiple regression model to simulate the quantitative relationship. Additionally, a negative correlation between road traffic carbon emissions and 1/TI (traffic index) was found after eliminating the effects of GDP (gross domestic product) and PTV (road passenger traffic volume). The results of Jieping Han (2012) [23] and Lin Pang (2017) [20] show that there is a positive correlation between GDP and road traffic carbon emissions, which is consistent with the results of this study. Their research results respectively show that the relationship between PTV and traffic carbon emissions is negatively correlated and positively correlated. However, the absolute values of the coefficients were all close to zero. According to the results of this study, road passenger traffic is positively correlated with traffic carbon emissions. The difference in the research results is related to the specific quantitative processing of indicators and the selection of regional data.

However, there are some errors and uncertainties in the model. There are only 10 years of data available since Beijing started calculating the traffic index in 2007. The number of explanatory variables was $k=3$, and the number of samples was $n=10$. However, when $n \geq k+8=11$, the $t$ statistic test of the partial regression coefficient would be relatively stable. The general regression requirement for the number of samples is $n \geq 3(k+1)=12$. There were only 10 sets of sample data in this paper, which has a certain impact on the results.

\subsection{Traffic Congestion and Carbon Emissions}

This paper used the traffic index to reflect traffic congestion. In a certain range, as the traffic index decreases by units, the carbon emission reduction accelerates. The quantitative relationship between the traffic index and carbon emissions has not been found in previous studies. Junfeng Wang (2017) used the gaussian mixture model (GMM) to investigate the endogenous relationship between traffic density and air pollution, and concluded that there is a linear relationship between traffic density and atmospheric pollution in eastern China [41]. Xiao Cuicui (2017) et al. established the Motor Vehicle Emission Simulator (MOVES) model [42]. Her study showed that there is a "U" relationship between 
the average vehicle running speed and the total vehicle pollution. The traffic index mentioned above is a comprehensive indicator of vehicle density and the average operating speed. It can be inferred that the introduction of the traffic index may be one of the reasons for the nonlinearity of the model.

\subsection{Traffic Congestion and Low-Carbon Economy Equilibrium in Beijing}

The result that the congestion will lead to an increase in carbon emissions is consistent with the results of Barth [32] and Jingrong Wang [33]. These studies used a calculation method based on vehicle fuel consumption data to calculate the road traffic carbon emissions caused by traffic congestion in different situations. This paper used the economic model to verify the quantitative relationship between traffic congestion and road traffic carbon emissions, and introduced the concept of the traffic index to calculate carbon emissions. No matter which research method was used, it can be proven that traffic congestion will lead to an increase in carbon emissions.

To evaluate whether the emission reduction targets can be achieved under the existing energy policy, taking Beijing, where electric vehicles account for less than $3 \%$, as an example, this paper constructed the equilibrium model between road traffic congestion and a low-carbon economy. It is obviously impossible to achieve the goal of reducing carbon emission intensity by about $40-45 \%$ in 2020 from 2005 only through the mitigation of traffic congestion. Carbon reduction targets need to be adjusted. Tiejun Liu (2017) studied air pollutants in Beijing and found that the change of the vehicle congestion level had little impact on the ambient air quality [43]. Even if there was "serious congestion", it was not the absolute dominant factor leading to the increase of air pollution. The conclusions of this paper are in line with the results of the source analysis. Both quantitative research methods were used to show that the carbon emission reduction target cannot be solved only by alleviating traffic congestion.

In addition, the relevant qualitative research literature has similar conclusions. Based on the study of Weidong Liu, Dadao Lu, and Lei Zhang (2010), the reduction of carbon emissions intensity is mainly from two major fields; that is, to reduce energy consumption and optimize the structure of the primary energy [6]. The most important way to improve the proportion of low-carbon energy in road traffic is the wide application of electric vehicles. Loureiro et al. (2013) confirmed that developing low-carbon fuel was a feasible plan for the development of a low-carbon economy of road traffic [44]. In this paper, the carbon emission coefficient of electricity was set to a fixed value, which cannot reflect the impact of an energy structure adjustment on the reduction of carbon emissions intensity in the transportation trade. This can be used as another aspect of research on carbon emissions.

\section{Conclusions}

Based on the research, the main conclusions can be summarized as following:

(1) By introducing the traffic index, the quantitative relationship between the degree of traffic congestion and the carbon emissions of road traffic was constructed. In the case of known GDP, PTV, and TI, a traffic congestion and low-carbon economic equilibrium model was established to achieve a balance between a low-carbon economy and traffic congestion. The method of establishing the equilibrium model has universal reference significance for other cities with congestion problems, where electric vehicles account for a relatively small proportion.

(2) The results of the research on the degree of the impact of the traffic index on road traffic carbon emissions can be used as a basis for decision-making by reducing congestion. For a region, when the traffic index is a certain value, road traffic carbon emissions can be calculated and the trend can be analyzed. Thereby, road traffic carbon emissions can be controlled by adjusting the degree of congestion.

(3) For the current road traffic in Beijing, where electric vehicles account for less than $3 \%$, it is impossible to achieve the established carbon emission reduction target by unilaterally reducing the traffic index. Due to high vehicle ownership, Beijing traffic congestion cannot be alleviated in 
a short period of time. However, with the slow decline of the future traffic index and the gradual easing of congestion, the carbon emission reduction effect will become more apparent. It can be foreseen that cities with lower traffic indices will achieve better carbon emissions reduction by alleviating traffic congestion.

(4) Taking Beijing as an example, the study found that carbon emissions reduction targets cannot be allocated to the road traffic trade directly. Regional carbon emissions targets should not be simply allocated to various industries; that is, they cannot be independently assumed by various industries. The emission reduction problem should be considered from a regional overall perspective.

Author Contributions: S.Y. grasped the overall context of the article, guided and completed the creation and modification of this article as a whole. Y.J. concentrated on literature review, methods, results and discussion, analyzed the data and contributed analysis tools. D.Z. and J.F. assisted in writing, modifying and submitting the article.

Funding: The research was funded by National Social Science Foundation of China (grant number is 16BJY055).

Conflicts of Interest: The authors declare no conflict of interests. 


\section{Appendix A}

Table A1. Linear regression data.

\begin{tabular}{|c|c|c|c|c|c|c|c|c|c|c|}
\hline Year & $\begin{array}{l}\mathrm{C} \\
\text { (t) }\end{array}$ & TI & $\begin{array}{c}\text { GDP } \\
\left(10^{8} \text { yuan }\right)\end{array}$ & $\begin{array}{l}\text { Trade GDP } \\
\text { (10 }{ }^{8} \text { yuan) }\end{array}$ & $\begin{array}{c}\text { PRP } \\
\left(10^{4} p\right)\end{array}$ & $\begin{array}{c}\text { PTV } \\
\left(10^{4} p\right)\end{array}$ & $\begin{array}{l}\text { FTV } \\
\left(10^{4} t\right)\end{array}$ & $\begin{array}{c}\text { TPT } \\
\left(10^{4} \mathrm{p} \cdot \mathrm{km}\right)\end{array}$ & $\begin{array}{c}\text { TFT } \\
\left(10^{4} \mathrm{t} \cdot \mathrm{km}\right)\end{array}$ & $\begin{array}{c}\text { PCV } \\
\left(10^{4} \text { Car }\right)\end{array}$ \\
\hline 2007 & $3,777,908.702$ & 7.3 & 9847 & 497.5 & 1676 & 9275 & 17,872 & $1,474,249$ & 792,883 & 251.6 \\
\hline 2008 & $4,433,794.898$ & 5.8 & 11,115 & 498.9 & 1771 & 117,118 & 18,689 & $2,409,604$ & 840,878 & 291 \\
\hline 2009 & $4,558,944.133$ & 5.4 & 12,153 & 556.6 & 1860 & 121,373 & 18,753 & $2,677,144$ & 878,887 & 372.1 \\
\hline 2010 & $4,905,359.881$ & 6.1 & 14,114 & 712 & 1962 & 126,130 & 20,184 & $2,906,492$ & $1,015,944$ & 452.9 \\
\hline 2011 & $5,029,339.045$ & 4.8 & 16,252 & 809 & 2019 & 129,918 & 23,276 & $3,036,655$ & $1,323,259$ & 473.2 \\
\hline 2012 & $5,396,006.481$ & 5.3 & 17,879 & 816.3 & 2069 & 132,333 & 24,952 & $3,047,757$ & $1,397,736$ & 495.7 \\
\hline 2013 & $5,236,856.388$ & 5.5 & 19,801 & 883.6 & 2115 & 52,481 & 24,651 & $1,360,831$ & $1,561,929$ & 518.9 \\
\hline 2014 & $5,527,998.068$ & 5.6 & 21,331 & 948.4 & 2152 & 52,354 & 25,416 & $1,382,967$ & $1,651,938$ & 532.4 \\
\hline 2015 & $5,655,713.611$ & 5.7 & 23,015 & 984.4 & 2171 & 49,931 & 19,044 & $1,301,210$ & $1,563,562$ & 535 \\
\hline 2016 & $6,007,250.541$ & 5.6 & 25,669 & 1061 & 2173 & 48,040 & 19,972 & $1,176,740$ & $1,613,192$ & 548.4 \\
\hline
\end{tabular}

Table A2. Equilibrium analysis (1).

\begin{tabular}{|c|c|c|c|c|c|c|c|c|c|}
\hline Year & $\begin{array}{c}\text { Upper Limit of } \\
\text { Expected Road Traffic } \\
\text { Carbon Emission }(t)\end{array}$ & $\begin{array}{l}\text { Expected Carbon } \\
\text { Emission Intensity } \\
\left(t / 10^{4} \text { yuan }\right)\end{array}$ & $\begin{array}{c}\text { Designed } \\
\text { Growth Rate }\end{array}$ & $\begin{array}{c}\text { Expected Trade GDP } \\
\left(10^{8} \text { yuan }\right)\end{array}$ & $\begin{array}{l}\text { Expected GDP } \\
\left(10^{8} \text { yuan }\right)\end{array}$ & $\begin{array}{c}\text { Designed } \\
\text { Growth Rate }\end{array}$ & PTV $\left(10^{4} p\right)$ & $\begin{array}{c}\text { Designed } \\
\text { Growth Rate }\end{array}$ & TI \\
\hline 2016 & $6,007,250.5$ & 0.66610 & & 1061.0 & $25,669.0$ & & 48,040 & & 5.6 \\
\hline 2017 & $5,677,920.5$ & 0.59116 & -0.1125 & 1130.0 & $27,337.5$ & 0.065 & 9608 & -0.8 & 3.6 \\
\hline 2018 & $5,366,645.1$ & 0.52465 & -0.1125 & 1203.4 & $29,114.4$ & 0.065 & 1921.6 & -0.8 & 2.4 \\
\hline 2019 & $5,072,434.4$ & 0.46562 & -0.1125 & 1281.6 & $31,006.9$ & 0.065 & 384.32 & -0.8 & 1.8 \\
\hline 2020 & $4,794,353.0$ & 0.41324 & -0.1125 & 1364.9 & $33,022.3$ & 0.065 & 76.864 & -0.8 & 1.4 \\
\hline
\end{tabular}

Data in 2016 are actual data, and 2017-2020 are forecast data 
Table A3. Equilibrium analysis (2).

\begin{tabular}{|c|c|c|c|c|c|c|c|c|}
\hline Year & TI & $\begin{array}{l}\text { Expected Trade } \\
\text { GDP }\left(10^{8} \text { yuan }\right)\end{array}$ & $\begin{array}{l}\text { Expected GDP } \\
\left(10^{8} \text { yuan }\right)\end{array}$ & $\begin{array}{c}\text { Designed } \\
\text { Growth Rate }\end{array}$ & $\begin{array}{l}\text { PTV } \\
\left(10^{4} \mathrm{p}\right)\end{array}$ & $\begin{array}{l}\text { Designed } \\
\text { Growth Rate }\end{array}$ & $\begin{array}{l}\text { Expected Carbon } \\
\text { Emission Intensity } \\
\left(\mathrm{t} / 10^{4} \text { yuan }\right)\end{array}$ & $\begin{array}{c}\text { Expected Road } \\
\text { Traffic Carbon } \\
\text { Emission }(t)\end{array}$ \\
\hline 2016 & 5.6 & 1061.0 & 25669.0 & & 48040 & & 0.66610 & 6007250.5 \\
\hline 2017 & 5.7 & 1130.0 & 27337.5 & 0.065 & 43236 & -0.1 & 0.65023 & 6245222.7 \\
\hline 2018 & 5.8 & 1203.4 & 29114.4 & 0.065 & 38912.4 & -0.1 & 0.63328 & 6477823.3 \\
\hline 2019 & 5.9 & 1281.6 & 31006.9 & 0.065 & 35021.16 & -0.1 & 0.61762 & 6728320.6 \\
\hline 2020 & 6.0 & 1364.9 & 33022.3 & 0.065 & 31519.044 & -0.1 & 0.60313 & 6997532.3 \\
\hline
\end{tabular}

Data in 2016 are actual data, and 2017-2020 are forecast data. 


\section{References}

1. Beijing 2017 National Economic and Social Development Statistical Bulletin. Available online: http:// zhengwu.beijing.gov.cn/sj/tjgb/t1509890.htm?from=groupmessage (accessed on 18 June 2018).

2. People's Daily: The Actual Total of Over 1 Million Vehicles, Non-Beijing Brand Cars in Beijing Should be Managed. Available online: http:/ / www.sohu.com/a/235874113_255783 (accessed on 18 June 2018).

3. Analysis of the Main Sources of PM2.5 in Beijing. Available online: http://bj.bendibao.com/news/2014417/ 144908.shtm (accessed on 18 June 2018).

4. Zhu, Y.; Zong, G. The design of Beijing Congestion Charge under Value of Time. China Soft Sci. 2014, 9, 67-77.

5. Shen, W.; Yang, H.; Zhang, B. Research on the factors affecting traffic congestion in Beijing. Automot. Ind. Res. 2016, 3, 25-31.

6. Liu, W.D.; Lu, D.D.; Zhang, L.; Wang, L.M.; Zhao, J.A.; Li, S.G.; Ma, L.; Tang, Z.P. Development Framework and Scientific Foundation of Low-Carbon Economy in China: Path to Reduce 40-45\% Emissions per Unit GDP in 2020; The Commercial Press: Beijing, China, 2010; ISBN 978-7-100-07143-7.

7. Wang, J.; Li, P.; Gao, J. Region division in China for transportation carbon emission reduction. J. Chang. Univ. Nat. Sci. Ed. 2012, 32, 72-79.

8. Yang, S.X.; Zhang, D.; Fu, J.; Fan, S.; Ji, Y. Market cultivation of electric vehicles in China: A survey based on consumer behavior. Sustainability 2018, 10, 4056. [CrossRef]

9. Cai, B.; Cao, D.; Liu, L.; Zhou, Y.; Zhang, Z. China transport $\mathrm{CO}_{2}$ emission study. Adv. Clim. Chang. Res. 2011, 7, 197-203.

10. Chen, F.; Zhu, D.; Xu, K. Research on urban low-carbon traffic model, current situation and strategy: An empirical analysis of Shanghai. Urban Plan. Forum 2009, 6, 39-46.

11. Gao, B.; Liu, W. Emissions reduction potential analysis of road transportation. Geogr. Res. 2013, 32, 767-775.

12. Sun, D.; Zhang, Y.; Xue, R.; Zhang, Y. Modeling carbon emissions from urban traffic system using mobile monitoring. Sci. Total Environ. 2017, 599, 944-951. [CrossRef]

13. Zhang, Q.; Tao, X.; Yang, P. Research on carbon emissions from metropolis urban passenger transport and countermeasures. China Popul. Resour. Environ. 2012, 22, 35-42.

14. Tao, Y.; Huang, Z.; Shi, C. Carbon dioxide emissions from regional tourism transport: A substitutional bottom-up analysis. Acta Ecol. Sin. 2015, 35, 4224-4233.

15. Wang, H.; Yu, L.; Zeng, W. Potential of reducing carbon emission from urban transport based on adjustments to jobs-housing separation in Beijing. China Popul. Resour. Environ. 2018, 28, 41-51.

16. Morrow, W.R.; Gallagher, K.S.; Collantes, G.; Lee, H. Analysis of policies to reduce oil consumption and greenhouse-gas emissions from the US transportation sector. Energy Policy 2010, 38, 1305-1320. [CrossRef]

17. Wang, B.; Guo, K. The efficient of carbon emission efficiency of Beijing public transportation system: Based on super-efficiency SBM model using Malmquist-Luenberger index. J. Syst. Sci. Math. Sci. 2018, 38, $456-467$.

18. Zhao, L.; Tang, J. Study on the carbon-reduction policy scenarios in Beijing bus company based on the LEAP model. Sci. Technol. Manag. Res. 2018, 2, 252-259.

19. Wang, J.; Ding, S. Research on the development of low-carbon traffic based on carbon emission in cities of Hebei Province. Enterp. Econ. 2013, 12, 14-18.

20. Pang, L. Analysis of Influencing Factors of Regional Transportation Carbon Emission Based on STIRPAT Model. Master's Thesis, Beijing Jiaotong University, Beijing, China, 2017.

21. Li, L. Study on the Evaluation Index System of the Road Transportation's Carbon Emission Levels. Master's Thesis, Chang'an University, Xi'an, China, 2014.

22. Zhang, X.; Yang, X.; Yan, Y. Statistical estimation method for energy consumption and carbon emissions by urban transport. China Soft Sci. 2014, 6, 142-150.

23. Han, J.; Zhang, X.; Zhou, J. Demonstration study on influence factors of highway traffic carbon emissions. J. Northeast Dianli Univ. 2012, 32, 91-94.

24. Zhang, T. Research on China's urban road transport carbon emissions under urbanization process. China Popul. Resour. Environ. 2012, 22, 3-9.

25. Yao, L. Analysis of Shaanxi Province Transportation Carbon Emissions Factors and Reduction Path. Master's Thesis, Chang'an University, Xi'an, China, 2016.

26. Wu, K.; He, C.; Wang, G.; Zhang, H. Measurement and decomposition analysis on carbon emissions of transportation industry in Shanghai. Econ. Geogr. 2012, 32, 45-51. 
27. Wei, Q.; Zhao, S.; Xiao, W. A quantitative analysis of carbon emissions reduction ability of transportation structure optimization in China. J. Transp. Syst. Eng. Inf. Technol. 2013, 13, 10-17. [CrossRef]

28. Yu, J.; Da, Y.; Ou, Y. Analysis of carbon emission changes in China's transportation industry based on LMDI decomposition method. China J. Highw. 2015, 28, 112-119.

29. Zhao, P.; Wan, H. Big city traffic characteristics and international management experience and enlightenment. World Reg. Stud. 2016, 25, 48-57.

30. Zhao, H.; Feng, S. How to effectively govern Beijing's transport congestion? An economic appraisal based on a congestion charge model with consideration of environmental cost. Urban Dev. Stud. 2015, 22, 101-110.

31. Zhu, M. Research on Socio-Economic Impact of Urban Traffic Congestion. Ph.D. Thesis, Beijing Jiaotong University, Beijing, China, 2013.

32. Barth, M.; Boriboonsomsin, K. Real-world carbon dioxide impacts of traffic congestion. Transp. Res. Rec. 2008, 2058, 163-171. [CrossRef]

33. Wang, J.; Xiao, H.; Xie, J. Research on carbon emission calculation model for expressway congestion. Mod. Transp. Technol. 2015, 2, 81-84.

34. Li, B.; Zhou, J. The carbon emission effect of traffic congestion: Taking the intersection of Xiangtan Bridge Hotel as an example. Urban Probl. 2017, 6, 46-51.

35. Chen, X.; Shan, X.; Ye, J.; Yi, F.; Wang, Y. Evaluating the effects of traffic congestion and passenger load on feeder bus fuel and emissions compared with passenger car. Transp. Res. Procedia 2017, 25, 616-626. [CrossRef]

36. Bigazzi, A.Y.; Figliozzi, M.A. Analysis of the relative efficiency of freeway congestion mitigation as an emission reduction strategy. In Proceedings of the Transportation Research Board Meeting, Washington, DC, USA, 23-27 January 2011.

37. Bigazzi, A.Y.; Figliozzi, M.A. Congestion and emissions mitigation: A comparison of capacity, demand, and vehicle based strategies. Transp. Res. Part D Transp. Environ. 2012, 17, 538-547. [CrossRef]

38. Liu, H.; Chen, X.; Wang, Y.; Han, S. Vehicle emission and near-Road air quality modeling for Shanghai, China, based on global positioning system data from taxis and revised MOVES emission inventory. Transp. Res. Rec. J. Transp. Res. Board 2013, 2340, 38-48. [CrossRef]

39. Intergovernmental Panel on Climate Change (IPCC). 2006 IPCC Guidelines for National Greenhouse Gas Inventories; Institute for Global Environmental Strategies: Hayama, Japan, 2006; ISBN 92-9169-520-3.

40. The Number of Pure Electric Vehicles has Reached 175 Thousand in Beijing. Available online: http:/ / www. bj.xinhuanet.com/bjyw/2018-06/22/c_1123020284.htm (accessed on 18 June 2018).

41. Wang, J.F. Research on the impact of traffic density on air pollution: An empirical study based on panel data of prefecture-level cities in China. Master's Thesis, Hunan University, Changsha, China, 2017.

42. Xiao, C.; Jia, L.; Xu, Z. An empirical study on the influence of vehicle speed on vehicle pollution emissions. Resour. Environ. Arid. Area 2017, 10, 131-137.

43. Liu, T.; Qiu, D.; Sun, J. Preliminary study on the relationship between urban traffic congestion and air pollution. China Popul. Resour. Environ. 2017, S2, 58-60.

44. Loureiro, M.; Labandeira, X.; Hanemann, M. Transport and low-carbon fuel: A study of public preferences in Spain. Energy Econ. 2013, 40, S126-S133. [CrossRef]

(C) 2019 by the authors. Licensee MDPI, Basel, Switzerland. This article is an open access article distributed under the terms and conditions of the Creative Commons Attribution (CC BY) license (http://creativecommons.org/licenses/by/4.0/). 